\title{
Recommendations: From sand, through silver, to gold plates
}

\author{
Jacques Berleur and Diane Whitehouse, Editors, \\ with the help of all the advocates and devil's advocates
}

\section{IFIP-WG9.2/9.5 Corfu International Conference Gold Plate (May 8-10, 1997)}

The information and communication technology society is potentially extremely inclusive, but in practice it is very exclusive, elitist, and sectarian.

To empower people we need universal service and equity of access that provide meaningful, quality information via diverse channels. We want to create 'free spirits'. To promote in the long term a real democracy presupposes an information society where citizens are able to participate in the decision-making process. Civic experiments are therefore needed in the short term which are controlled by all reactive, anticipatory and, above all, participatory means. In others words, we need a critical mass which in turn is also a mass that is critical.

IFIP-WG9.2/9.5 Corfu conference advocates at the highest level an 'action plan' for an ethical global information society that supports:

- people-centered development and public advocacy, i.e., promoting discussion and participation,

- cultural diversity,

- universal low cost access,

- local civic networks,

- development of a framework of rights and responsibilities for a global information society favouring a responsible citizenship.

'Thales of Miletus in the first half of the 6th century was a member of a group of Greek philosophers who combined wisdom and intellectual inventiveness to find solutions to social problems. The group developed a process of philosophical analysis; first thoughts were written conceptually in sand and discussed; some were wiped away to be replaced by others. Those judged best by consensus were 
transcribed onto ten silver plates, then the best of the silver were transcribed onto a single gold platter; this quintessence of wisdom was carried to the place of public pronouncements, the agora. "1

Our conference was based on this process of refinement, as suggested by Thales of Miletus. Ideas were debated, distilled, and crafted. Entirely new ideas were also added to plates. The conference concluded with the public advocacy and debate of gold plates (the final distillation of the sand and silver plates). A public choice of the most popular ideas displayed on a gold plate was made during the final session of the conference.

Sand plates were transcribed as written personally by different participants at the end of the first day; silver plates were already the 'product' of working group discussions, as well as the 'gold plates' which were advocated in the agora.

\section{THE PROCESS}

The whole process of developing sand, silver, and gold plates means progressing from ideas (written on sand plates), to challenges (on silver plates), and finally to actions (gold plates).

\section{Day 1: Sand day}

The role of the first day's papers was to stimulate conference attendees to think about their best ideas in terms of promoting culture and democracy in the global information society. At the end of the first day, every conference attendee was invited to write in one or two sentences on a 'sand plate' his/her best idea about culture and democracy in the information society.

These 'sand ideas' are given in annex 1 of this chapter.

\section{Day 2: Silver day}

The creation of the silver plates took place on the second day within working groups. Out of the synthesis of groups' thoughts on the sand plates, each working group was invited to produce four or five silver plates.

These silver plates had to emphasize the main cultural and democratic challenges to the global information society as they appeared on the sand plates, and in the two first days of conference papers. At least one silver plate was supposed to include a creative metaphor.

The silver plates are also given in annex 2 of this chapter.

\section{Day 3: Gold day}

First session: From silver plates to gold plate

All the silver plates were mixed up, and divided into three stacks which were provided to three working groups. 
As the final process of refinement, the job of each working group was to produce a single gold plate. It was asked that the potential gold plates should each demonstrate a proposal for action.

Each group had to decide which of their members would act as the advocate for the gold plate and also designate a 'devil's advocate'. The groups then accompanied their advocates and their plate to the agora.

\section{Final session: the agora}

In the agora, the plenary audience heard the arguments for and against each gold plate from all the advocates and devil's advocates. A vote to award the winning gold plate followed. The proposal put forward on the winning gold plate is included in the box at the head of this chapter.

\section{SAND AND SILVER PLATES: MAIN TRENDS}

\section{... in terms of ideas}

Globalization is not per se viewed as determined by technology. But specific metaphors, such as 'global village', 'information highway', 'information society' may be policy instruments for hidden goals which are purely linked to economic or political interests.

Repeatedly, the participants argued that people must be empowered, and that people and communities must be the driving forces for technological innovation. With the Internet in mind, they advocated easy access for all as well as 'universal service'. The diversity of voices is the guarantee of true democracy. Culture is seen as the way of empowering people, through awareness campaigns, training of the public, local experiments, participatory design, introduction of specific skills for analyzing the social implications in professional practices, etc. But information overflow is also seen as an ethical and political problem which could lead to disempowerment.

'Virtuality' was also considered an ideological concept: virtual community, virtual democracy, etc. Therefore, it seems rather urgent to investigate, much more than has been done so far, the consequences and influences - positive and negative, of the 'virtual worlds (or words?)' on real personalities, real cultures, and real democracies, and to involve many more segments of society in the process. From another point of view, we are far from really understanding all the risks of the Internet which was developed without the minimum guarantee of reliable and secure functionality.

Democracy seemed to be the focus of the majority of the conference participants: deregulation, exclusion, elitism, and sectarianism were seen as the main threats of the so-called global information society. The old problem of information poor and information rich is re-appearing dramatically on the scene. The international distribution of labour and cheap intellectual labour bought in the developing nations are affected through new means such as the Internet. Elitism, nationalism, and other ideologies serve the most sectarian interests of the global information society. Participation and solidarity expressed through local communities could prevent us from being passively led where we do not want to 
go. Is it a utopia to think about an information society redesigned from the grassroots level? Can the Internet become a real agora? The round table on the subject, in this volume, may help to outline some of the issues at stake.

The global information society project must be revisited, so that we look at it from the point of view of the users and the usees ('the people affected or effected by the spreading of the new technologies', as they are now referred in the IFIP-TC9 circles) ${ }^{2}$. There is a strong advocacy for providing a more effective and more motivating role for citizens to monitor and influence what is going on.

Daedalus or Icarus? Technology is open to misuse!

\section{.... in terms of challenges}

The challenges are clearly expressed in the silver plates. They are addressed to governments, institutions, and corporations, as well as to the members of professional societies or to non-government organizations. The challenges are to:

- provide, at the global and local levels, complete, understandable, transparent and quality information to all citizens so that they will be able to participate in the decision-making processes,

- provide technical means, free or low cost access to the communication channels (the Internet or others to come), in public spaces and at home,

- allow free expression,

- respect diversity of cultures as opposed to the current trend towards homogenization,

- commit the public and ICT professionals to a process of education for the common shaping of a real democratic information society,

- include social implications and ethics in the learning and training of professionals,

- develop local civic networks.

As requested by the organizers of the conference, one group created a metaphor. Moreover, the group accompanied the metaphor with a drawing! Their challenge is 'to make the best use of the river of information ...' Both the metaphor and the drawing are included at the end of annex 2 of the present chapter.

\section{ARGUMENTS AND RATIONALES FOR ACTION: TOWARDS THE WINNING GOLD PLATE}

In the agora, three groups presented their gold plates. Each group nominated an advocate and a devil's advocate to argue for and against the gold plate. Each set of ideas was presented in order. There was much commentary from the floor. Public debate came fast and furious.

Some attendees argued for the need for harmony and synthesis; others for dialectic, discussion, and debate. Some welcomed the advocates' views, others the standpoints of the devil's advocates.

One spokesperson wanted the plenary group to search for any missing information that had not been presented, X-information, such as a public awareness campaign that would focus on the information society or the river of information that flows along to all users. Yet another recognized that it was the very diversity 
of ideas that had been discussed in the agora that was important for there were a million or more ideas the plenary group had failed to discuss. It is this kind of debate, she argued, that should continue both in the information systems profession and in society at large.

Quickly, there came a suggestion for a vote on the three gold plates. But at least one attendee was suspicious of free voting, whether in everyday life or on the Internet. Another preferred that any final decision should be taken by an executive of wise persons. Many of the participants in the agora did not wish to have to vote in favour of a single gold plate: they liked all three of the ideas.

Here, we outline in order the arguments put forward in the agora by each of the three groups through their advocates and devil's advocates.

\section{Advocate 1 (Jan Holvast)}

\section{Presuppositions:}

The information and communication society is potentially extremely inclusive $(98 \%)$, but in practice it is very exclusive, elitist, and sectarian (2\%).

Access to information is power.

Action Programme:

Long term: Empowerment of the people. Democracy is power (crátos: strength, power) of the people (dèmos: land inhabited by people, citizens, people)

Middle term: To create an information society which provides relevant, complete and transparent information to make citizens able to participate in decision-making processes

Short term: (Local) experiments with civic networks in order to facilitate people:

- to get the information they need,

- to make a free choice about the way they want to use the information,

- to make clear that information can be dangerous and wrong,

- to decide to be inclusive or exclusive (defined by themselves),

- to stimulate self-determinism.

This process needs to be designed, implemented and controlled by means of anticipation (WG9.2, 'usees'), legislation and participation ('usees') in order to secure diversity.

We need a critical mass as well as a mass that is critical.

\section{Devil's Advocate 1 (Leif Bloch Rasmussen)}

\section{Citizens!}

I have had some trouble in finding out how to look like a devil. Should I be the devil, his advocate, Mr Bangemann, a 'Sophocrat', his mother, or someone else other than the devil? Or should I just take any look at all? In fact, the devil's mother must be Sophia - the wife of God in the Bible. Sophia is wisdom, so this might be a good way of being the devil. However I have found that the devil might be myself, plain as I am, and that the devil might be in all of us.

So: Dear fellow devils! Two things are important in democracy and civilization and in my group's proposal for the empowerment of people: information and administration (control). 
But they neglect two opposite concepts: 'X-information' and 'ministration', which are much more important for the empowerment of people.

' $\mathrm{X}$-information' is all that knowledge that is left out in our rationalization towards getting data and information. It is forgotten, embodied, tacit knowledge. It is myth, legend, story-telling, metaphors, and rhetoric in their best sense. This is what is guiding our actions, thoughts, and feelings. We need local and global diversified 'X-information systems', not uniform, global (0-1) information systems.

Similar notions hold for 'ministration'. This means the ministering to people for their personal, unique, feeling and needs. Administration means most often control of people. Against a uniform way of looking at people and the world, we need ministering, not administrative systems.

So I say: think again. Do not act according to this gold plate. Create ' $\mathrm{X}$ information' and 'ministering' before you try to design any information system or administrative system for the empowerment of people. Otherwise the technology the computer - may turn into being the master.

Hope it's not too late!

\section{Advocates 2 (Diane Whitehouse and Julie Cameron)}

Today's reality is about an enormous number of people who are excluded from access to information and communication technologies (ICT), what the group referred to as usees: for example, anyone who uses a technology directly or indirectly but who has no influence on the rules for its use, its development, or those who control it; or anyone who has no knowledge of the technology itself or who does not understand the implications of using it. Some practical examples can include anyone who is not a business person or a professional person; anyone who does not have a substantial income; anyone who is neither young nor male; those who live in either in non-urban areas or in areas of urban decay; and those who live in developing countries.

On the other hand, the group also felt strongly that individuals may want to be or may decide to be excluded: and this is their right too. Nevertheless, the group hoped that, by encouraging access to ICT, people will be able to take charge of the technological aspect of their lives.

A minimum set of services provided to all citizens at an affordable price to be defined within individual nation-states is one prequisite to access. The other prerequisites are access to skills for using ICT and an understanding of how to use cyberspace, what are its strengths and weaknesses, and what is its source and credibility. The group saw this as similar to the recent set proposals developed by the Commission of European Communities: 'a defined set of services of specified quality which is available to all users independent of their geographic location and, in the light of specific national conditions, at an affordable price'.

Equity of access refers to both physical and mental ability to access information. Citizens need to know how to access the information provided in cyberspace. Educators need to ensure equity of knowledge, and communities need especially to ensure equity for disadvantaged groups.

Developing individual citizens with spirits that are as free as possible - 'free spirits' - ensuring a diversity of culture and thought expressed in open debate and 
in a free flow of information, not simply on the Internet but in everyday life too was thought to be extremely important.

The group was comprehensive in the range of individuals and groups it wanted to include in this process of empowerment: citizens, educators, designers, librarians, information providers, ICT providers, and information service providers. The group looked forward to 'people power' shaping new technologies through the work of groups, cooperatives, and collaborative initiatives.

The group was concerned about the overwhelming influence of multinational software and hardware providers in their dominance of ICT provision, and there was some hope that the United Nations and professional associations like the International Federation for Information Processing (IFIP) might play some role in diminishing this monopoly. This role would involve informing decision-makers developing policy positions, and ensuring that ICT professionals act with awareness and in accordance with appropriate ethical guidance from charters, codes of ethics, and codes of practice within informed legal frameworks. No single organization - multinational or government - should control either information infrastructure or its content.

The group was aware of today's proliferation of 'stupefying entertainment, needless gadgets, and useless services'. The group was concerned about the abundance of pseudo-information, information that has not been validated, and data that are neither safe nor secure. Users have a responsibility to ensure that information is accurate and meaningful. The sheer volume of unrefereed material 'published' means that some is dubious. Users need to be aware of the need to query the source of data and its quality, they need to ensure that the data they maintain and provide meet quality standards, and they should also monitor the data provided to them by others. As solutions which draw from theory, the group saw the need for more effective application of communication theory, redundant channels, and of feedback loops.

After much deliberation, the group decided it was most important to sum up its thoughts in a clear, succinct statement which it outlined as:

'To empower people, we need universal service and equity of access that provide meaningful, quality information via diverse channels. We want to create free spirits!'

\section{Devil's Advocate 2 (Niklas Damiris)}

First, a comment concerning the way I would like the following to be read. I take it that the role of the devil's advocate is not to try to demolish the position put forward by the group. Rather, by pointing out omissions and by questioning selfevident assumptions of the gold plate statement, he is in fact strengthening the position of the group through constructive critique! In my role as devil's advocate, I would like to make three points which the gold plate does not take into account.

First, I find it rather arrogant and presumptuous to talk about and think of people as in need of empowerment and in need of being freed through information technologies. Expressing matters this way implies that most humans are either victimized or 'wimpy'. I see, instead, individuals as already force-full and powerful. This means I see people from the start as naturally full of potential that is afforded them in lieu of their being embodied and embedded in the world. People 
become free by recognizing their freedoms as indissociable from their powers and responsibilities. So there is no need to create free spirits. Then the problem becomes explicitly ethological/ethical: namely, how the various powers expressed by and through individuals and groups can be coupled and combined without frustrating and damaging each other. That means conflict; but agon, as the ancient Greeks and ethological studies of animal conduct confirm, engenders democracy (now literally the power of people!).

This brings me to my second point. Because we live in a mass society, conflicts between groups are becoming the rule not the exception. That conflict is the issue; giving people access to more and more information is not the point.

Finally, I want to point to an omission. No reference has been made to economic matters. The desire to provide meaningful information and respect cultural diversity is pure wishful thinking if it is articulated independently from financial considerations. Economics indeed has a very complex relation to the aforementioned desire. My point here is not merely to raise the issue of who will and how we will pay for the costs of universal access. More provocatively, I want to use the occasion to question the role and function of economic variables in a mass society.

\section{Advocates 3 (Karin Geiselhart and Marc van Lieshout)}

That was very good info-entertainment but let's change channels. We know that we are in agreement with the other channels. How can we all act politically?

Our basic point is to state that our conference is a working conference, and that we are expected to produce outputs that could be used to carry forward the work of the group in other forums.

We want IFIP to advocate at the very highest level of action. We want to propose a plan that is based on a people-centered development, public advocacy, that

- illustrates cultural diversity,

- provides low cost access,

- local civic networks,

- within a framework of rights and responsibilities for a global information society.

We want 'information for independent people'. We want to promote the work of the United Nations, the European Community, the G7 and others, work that is enshrined at every possible social level. This is the motivation behind our group's gold plate: to create a statement of intention that can be proposed to international institutions, for debate and, hopefully, eventual commitment to a set of principles that all could strive for in various ways. The Action Plan to be formulated should be the result of activities within IFIP itself, entailing the aspects as formulated in the message.

We want people to know that their privacy and their individuality is at stake in the information society.

The group came to this message following an inventory of the most promising silver plates. The inventory showed the following aspects:

- Diversity was formulated as a basic need of society; not as a situation that either exists or not, but as essential for a society to be existent; 
- It is not only essential that information is offered to people, it should also be the other way around: people should be enabled to offer information they consider to be important to others. Local communities were considered to be important places for the organization of the democratic process. The conscious reader will have noticed that in our statement it is presupposed that democracy does not simply surface but it must be organized;

- Important aspects within a global information society are the possibilities to increase public advocacy and awareness; not as something to be imposed, but as objectives to be realized by creating stimulating conditions;

- Low cost universal access was seen as one of the conditions sine qua non for realizing an equitable and ethical global information society that enables all people to become part of it;

- Empowerment of the people presupposes a community. Though the globalization enables global communication patterns, it was seen as essential to have a focus on local (existing) communities.

The principle challenge for a group of high-minded idealists, which we all seem to be, is how to progress with such a 'normative' agenda in the real world. It seems like we are the good ones at that task!

\section{Devil's Advocate 3 (Richard S. Rosenberg)}

Get real. A group of Europeans with North Americans and Australians, under the auspices of IFIP, have asked (who?) for a more equitable world - access to the Internet for all, a responsive democratic process, and more. Why should anyone pay attention? Will the global communications and information corporations suddenly recognize their responsibilities and reduce profits to make the world a better place? Will such governments as the United States realize that a wired world is a better world and that they have an obligation to help people everywhere to connect? I think not.

It is irresponsible to suggest that 'feel good' messages or gold plates will have a real impact. If it is our goal to produce mandates and resolutions with all the right sentiments, then we have probably succeeded. If we wish to participate actively in changing the world by employing the Internet as a necessary tool, then we have a long way to go. Understanding, analysis, synthesis, and dissemination are obvious precursors to direct advocacy but they are not enough. Another statement to the world by well-meaning intellectuals is just that, another demonstration of good intentions.

So what am I for? Simply put, action. Let me preface the following comments with a cautionary note about the word advocacy. There is a common misunderstanding about the nature of public advocacy or activism. It does not and should not mean a self-appointed group of supposedly wise men telling people what it is in their self-interest to demand or to do. Rather, advocacy in the present context is the exercise of a professional's responsibility in informing the public of some of the implications of an evolving technology. The following words of the political scientist, C.B. MacPherson, in discussing the views of John Dewey with respect to the nature of a liberal democracy, are quite relevant:

The root difficulty lay not in any defects in the machinery of government but in the fact that the democratic public was 'still largely inchoate and unorganized,' 
and unable to see what forces of was no tinkering with the political machinery: the prior problem was 'that of discovering the means by which a scattered, mobile, and manifold public may so recognize itself as to define and express its interests.' The public's present incompetence to do this was traced to its failure to understand the technological and scientific forces which had made it so helpless. ${ }^{3}$

It is our job to help the public to understand, and it is its job to demand its rights, which include those that have been articulated in the gold plates produced at this workshop.

\section{THEN, WE VOTED}

Eventually, the session did end with a vote. It was a vote in favour of all three gold plate ideas being expressed in a single location, included 'on a single plate' (though not merged or amalgamated) (for: 27; against, 11). The result is the expression of all three gold plates outlined in the box at the beginning of this chapter.

It was decided to leave up to the editors to present them in a consistent way and to prepare a file to address the final gold plate to organizations, institutions, authorities which are preparing our future throughout the world: associations, civic networks, groups of people which are working or sometimes fighting for the reappropriation by the people of what must remain our tools and techniques.

This final plate cannot be read without glancing at all the other plates, either sand or silver, which prepared it. Even if the literary, rhetorical style of the agora, with its advocates and devil's advocates, makes the arguments sometimes funny, dubious or artificially contentious, they have to be considered because they also contain their part of truth!

The issues at stake are multiple: technological, economic, social, political, global, etc. But they are also ethical. The round table on ethics which gathered all the people who contributed to the first part of this volume, identified the main ethical issues. Sometimes ethical issues, such as privacy, computer crime, copyright, censorship, and so on are covered by the law. But new problems appear more explicitly such as equity of access, respect for the diversity of cultures, equitable distribution of benefits, ownership of data when considered as a resource (for development, for instance) as opposed to a commodity, global governance, etc. We need to delineate clearly ethical/social or ethical/political questions, without confining ethics to the domain of individual responsibility. Ethics also refers to the way we act together, socially and, today, worldwidely.

We revisited the project of a global information society which, for the Europeans at least, was presented and adopted by the European Council in Corfu (June 24-25, 1994) ${ }^{4}$. Visitors came from nearly twenty countries, and from four continents. Africa was absent!

We did not revisit thoroughly the official documents prepared by all our countries. They informed our thinking but they were intensely criticized, and they were not considered as top-down messages but instruments which people can use 
themselves to critique, evaluate, and assess the rhetoric of the global information society.

Maybe we could dare to say metaphorically: From Corfu 1994 to Corfu 1997.

\section{IFIP-WG9.2/9.5 Corfu International Conference Gold Plate} (May 8-10, 1997)

The information and communication technology society is potentially extremely inclusive, but in practice it is very exclusive, elitist, and sectarian.

To empower people we need universal service and equity of access that provide meaningful, quality information via diverse channels. We want to create 'free spirits'. To promote in the long term a real democracy presupposes an information society where citizens are able to participate in the decision-making process. Civic experiments are therefore needed in the short term which are controlled by all reactive, anticipatory and, above all, participatory means. In others words, we need a critical mass which in turn is also a mass that is critical.

IFIP-WG9.2/9.5 Corfu conference advocates at the highest level an 'action plan' for an ethical global information society that supports:

- people-centered development and public advocacy, i.e., promoting discussion and participation,

- cultural diversity,

- universal low cost access,

- local civic networks,

- development of a framework of rights and responsibilities for a global information society favouring a responsible citizenship. 
Sand Plates

Annex 1

We give here the sand plates as they were written by the participants, but also as regrouped by the editors according to 'generic ideas'.

\section{A. Globalization - Information Society - Metaphors}

- What type of social ties characterizes the information society (IS)?

What could be a possible definition of 'community' in the IS?

What could be an artistic activity-practice in the framework of the IS?

- Information technology (IT) is not the driving force, it is driven by ideologies like 'deregulation', 'economic globalization', and 'decentralization'. Attempts at influence should address those ideological practices.

- Metaphors like the information highway and IS are important political instruments which are used by technologists, economists and politicians - in short 'digitalists' - in order to control and organize public opinion, and thereby secure hidden political goals of growth and competitiveness in the market.

Counter-metaphors would be designed, and this can be done using the knowledge of rhetoric from the past. Knowledge and ethics of metaphors and rhetoric must be mandatory for information and communication technology (ICT) professionals.

- In a time of radical social changes (globalization and cultural extinction, market dominance, and threats to democracy), it is essential that we find out where we want to go, and how to use technology to get there. (Rather than leaping backwards into the future, it is time for all of us to look before we leap.)

- We are moving into a world without rules, without speed limits and without boundaries. We need to develop community standards to live in this environment.

- To counter the threats of the ideological forces of 'deregulation', 'economic globalization' and 'decentralization' that largely determine the use of IT, we need structural, institutional, and cultural changes, providing a more effective and more motivating role for citizens to monitor and influence what is going on.

- Threats. Space and time are shrinking with great speed in the global information society (GIS). Consequences: international distribution of labour will be affected; cheap intellectual labour may be purchased via the Internet from universities in economically deprived countries. Creation of elitist, nationalist, and other ideologically biased concerns; combination of such networks will promise sectarian interest versus those of the GIS.

- IS is not - should not be - a matter by itself,* but only one topic which intervenes in the evolution of complex matters which have priority such as democracy, education policy, privacy, consumer protection, ...

(* except for economic - and political - forces which have to sell IT!)

\section{B. Empowerment of people}

- The IS represents a new opportunity to design our world from the grassroots. From the people to the people.

- Usenet and the Internet are important new means of mass communication. They grew up from the marriage of computing and communication technology and the hard work of many Netizens to create a way for people to have a voice and to communicate. There is a need to protect and support and make them available to all.

- How do we, IT professionals, make society feel that they really are/should be the stakeholders in influencing IT for the positive evolution of society? Should we?

- Regardless of how we define culture, democracy or the IS, we need to consider the issues related to users of the technology and to 'usees' - those affected by it. Those issues are universal.

- We must think about culture and democracy as processes and not in terms of their products.

- The key elements for promoting democracy in the GIS are to:

- raise awareness through participatory methods concerning decision-making at the local level,

- train citizens through pilot experiments in relation with local authorities. 
C. Culture - Virtual worlds

- The most important task of the GIS is not to create virtual personalities, virtual cultures, virtual democracies; but to facilitate an understanding of real personalities, real culture, real democracies. How do we guarantee this?

- Culture and democracy in the GIS are endangered, because of losing the feeling for reality while using the Internet.

- $\quad$ Culture $=$ People's means of self-expression and community development.

- Even though the Internet community creates cultural interchange, however, there still remains cultural aspects of that social context.

- A virtual agora for the poor and excluded may be wishful thinking because the risk of demagogy is too great.

- We need to be both optimistic and critical in assessing the contribution of new ICT to strengthen virtual democracy and citizens' participation.

- There is no new virtual culture. Virtual culture is our culture put on the 'net'.

D. Democracy

- The 'net' gives us the opportunity to reconsider our ideas about politics. In particular, we can question the system of elected representatives. We can consider the option of a referendum. Thus Usenet could be a boost towards direct democracy.

- It is imperative that new models of democracy be developed for an IS which applies to organizations as well as nations.

- It is clear that technologies by themselves will not create democratic or social improvement or cultural creativity.

Citizens and organizations have to transform themselves through participation and solidarity showing the way in order to be fully acquainted with the use of ICT.

- Community is the best protection against abuse of privacy.

- Getting the laws from a stranger? Benefits and disadvantages.

- In what ways (give examples) could the IS enhance democratic participation of the ordinary citizen and reduce the democratic deficit which is felt by major layers of societies nowadays (expressed, for example, by abstention from voting)?

- Aware of the fact that the Internet was developed without minimum guarantee of reliable and secure functionality, recognizing that essential actors governing Internet development are following goals and plans which do not include sufficiently improved safety and security, observing the growing amount of malicious, illegal and criminal use of the Internet, as well as understanding inherent limitations of assessing the quality of stored or communicated information, the following agenda should be enacted:

- a public information campaign should be stated to inform people about serious basic risks of the Internet,

- equal, safe and secure use of the Internet should be enforced by legal and technical means in the next generation of systems,

- and projects for democratic applications should be rigidly analyzed for their constitutional and legal acceptability.

- To consider ICT as an instrument for long-term equity and sustainability is the only 'ethical' attitude.

- Privacy enhancing technologies and international harmonization of privacy legislation.

- The only challenge of IT is a political one: How to give power (crátos) to the people (dèmos)?

- Achieving authentic democracy will require re-doing technology and democracy as we currently practice them.

- The Internet reaches about $1 \%$ of the world population today and is unlikely to reach more than $20 \%$.

- 'Including people in'. Or, in other words, virtual happiness in a teledemocratic society which only excludes people not able to be 'in': Is that the choice?

\section{E. Miscellaneous}

- It is important to understand what is new about the computer-mediated communication (CMC) / ICT and try to go ahead in promoting and protecting the medium for that new contribution. The old has its place. The new should need help. 
- There is too much information on the web which cannot be identified. A first step in reducing information overflow would be to 'rate' it and to indicate author, producer, status (draft, final), date, duration of validity, etc. A summary should accompany the material on disposal.

- Please apply both

(a) structural and procedural methods and

(b) mutual communication for creating shared meaning to solve a problem.

Please try to guarantee that (a) and (b) are both taken into account and applied in a balanced way.

- Address the shadow! (The unsaid and unthought in what is said about the IS.)

- Daedalus or Icarus?

\section{Silver Plates}

\section{Group 1}

1. Empowerment of the People

A challenge to government, institutions, companies and members of society. To make available free or very low cost access to the 'net' (in public spaces and homes) and to make the possibility and capability available for everyone to be able to communicate and express their views. Also, the people themselves need to be part of developing the present and future communication systems.

2. ICT Society is potentially extremely inclusive, but in practice it could be also very exclusive, elitist, and sectarian.

The challenge for true democracy is to create an IS which provides relevant, complete and transparent information to make citizens able to participate in decision-making processes which enrich their own lives. An active citizenship for all presupposes shared information which is socially validated through cross-examination mechanisms. Problem-solving must result in efficiency which benefits all.

Taken at the global level, this democratic challenge must be implemented through a managerial articulation between the global and local levels.

3. Information providers should respond particularly to the needs of the public, especially with respect to that information that is needed for the democratic process. This information should be accessible and comprehensible to the public and the quality of information should be made explicit.

\section{Group 2}

4. 'Society is a thin film bordering on chaos' ... technology, apocalypse, Frankenstein ...

5. We need to engage diverse perspectives in the design and control of ICT systems (i.e., the perspectives of those who use them, who are and will be affected by them, of different disciplines, cultures, gender ...).

6. Both the education of ICT professionals and the active involvement of the general public are necessary precursors to the shaping of a democratic information society.

7. To avoid becoming prisoners we need to be vigilant, to ensure those who wish to be included can be and those who do not wish to use ICT have that choice as well.

Group 3

8. The IT community should wash their words - preserve the diversity of languages!

9. a. The challenge we see for global democracy: Involve the participation of both people using IT and the participation of people who do not have access to it. Against the risk of homogenization the challenge is for cultural diversity to be maintained and promoted in the emerging information society.

b. To attain this, the expression of different cultures has to cope with the extension of democratic participation on a world scale. 
10. Challenge: To include social implications and ethics in the learning process of professionals. To avoid narrowsightedness, non-IT professionals, including concerned and affected people, ought to be integrated into this learning experience.

11. Local civic networks should be designed, implemented, and managed to secure diversity.

12. Escher - Recurrence

The challenge is: To make the best use of the river of information - see drawing!

Objective: sustainable relation between the river and the communities profiting from the river.

Core functions: irrigation - damming - driving - washing - purifying - power: constant negotiation. Coordinated use of control mechanisms: dams - dikes - directions.

Attention to data-fishing, free access, bridges to join communities, early warning systems for freezing or drying up downstream pollution.

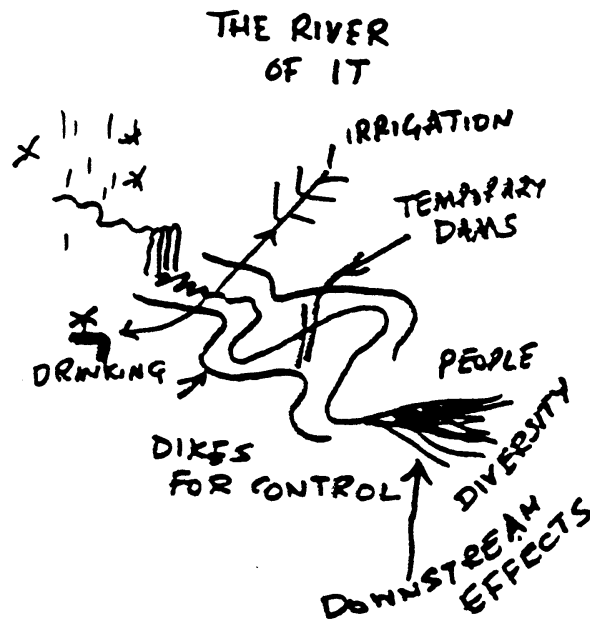

1 Can Information Technology Result in Benevolent Bureaucracies? T. R. H. Sizer, L. Yngström, J. Berleur and R. Laufer, Eds., Proceedings of the IFIP-WG9.2 Namur Working Conference, North-Holland, 1985, Chapter 1.

2 See: Discussion and Conclusion, in: Information Technology Assessment, Jacques Berleur and John Drumm, Eds., Proceedings of the Fourth IFIP-TC9 International Conference on Human Choice and Computers, Dublin, July 8-12, 1990, Elsevier Science Publishers (North-Holland), 1991, p. 388.

3 C.B. MacPherson, The Life and Times of Liberal Democracy, Oxford, England: Oxford University Press, 1980, p. 73.

4 Commission of the European Community, Europe and the Global Information Society Recommendations to the European Council - The Bangemann Report, 26 May 1994, CD-84-94290-EN-C. See also: Europe's Way to the Information Society. An Action Plan, Communication from the Commission to the Council and the European Parliament, and the Economic and Social Committee and the Committee of Regions, Brussels, COM(94) 347 final, July 19, 1994. And: Europe's Rolling Action Plan for Information Society, COM(96) 607 final, Brussels, November 27, 1996. These documents are worth being compared to other ones such as for instance: National Telecommunications and Information Administration (NTIA), National Information Infrastructure : Agenda for Action, Washington, DC, Department of Commerce, September 1993. 